\title{
Structure, Orientation and Stability of Lysozyme Confined in layered Materials
}

\author{
Sébastien Balme ${ }^{\mathrm{a}, \mathrm{b} *}$, Régis Guégan ${ }^{\mathrm{c} *}$, Jean-Marc Janot ${ }^{\mathrm{a}}$, Maguy Jaber ${ }^{\mathrm{d}}$, Mathilde Lepoitevin ${ }^{\mathrm{a}}$, Philippe \\ Dejardin $^{\mathrm{a}}$, Xavier Bourrat ${ }^{\mathrm{c}}$, Mikael Motelica-Heino ${ }^{\mathrm{c}}$
}

\author{
Received (in $X X X, X X X)$ Xth $X X X X X X X X X 20 X X$, Accepted Xth $X X X X X X X X X 20 X X$ \\ DOI: $10.1039 / b 000000 x$
}

\begin{abstract}
The confinement of lysozyme in 3 layered materials based on montmorillonite and lamellar double hydroxide exhibiting different surface charges was studied. The protein structure and orientation in these materials were determined by X-Ray diffraction, time resolved fluorescence and fluorescence anisotropy. For both Montmorillonite exchanged with sodium and modified with non-ionic surfactant (tri-ethylene glycol mono n-decyl ether), the lysozyme was found to be located in the interlayer space with "end-on" and "side-on" orientation, respectively. Conversely no lysozyme intercalation was observed with lamellar double hydroxide modified with anionic surfactant (sodium octylsulfate), since protein was adsorbed on the surface of the particles. Fourier transformed infra-red spectroscopy analysis shows that lysozyme confinement in the interlayer space preserves its structure after dehydration, whereas some structural changes were observed for lysozyme adsorbed on the particle surface.
\end{abstract}

\section{Introduction}

The confinement of biomolecules in inorganic porous materials, for the synthesis of novel nanocomposites with particular properties or the manufacture of biosensors, has attracted 5 considerable attention in the past decade. ${ }^{1-12}$ Indeed, many studies have shown the multiple possibilities and applications of these hybrid materials where guest molecules are confined into various inorganic host matrices such as metallic phases and porous alumina or silica., ${ }^{9,13-15}$

10 Layered materials such as natural clay minerals or layered double hydroxides (LDH) and their resulting organo analogues by introduction of surfactants can serve as efficient host materials to intercalate biomolecules and preserve their respective functions and structures. ${ }^{1-3,6}$ Moreover, layered materials are of special 15 interest due to their high internal surface areas, their abilities to confine guest biomolecules within regularly organized interlayer spaces, and to undergo self-orientation at a macroscopic scale. Thus natural and chemically modified clay minerals, i.e. organoclay materials, have been largely exploited for the intercalation of 20 biological molecules such as amino acids or proteins to build biosensors or to spread clay-protein films on electrodes for electrochemical catalysis. ${ }^{1-4,6}$ The intercalation of biomolecules in layered materials is mainly driven by electrostatic interactions, through the substitution of inorganic ions. The chemical 25 modification of clay minerals or LDHs by intercalation of surfactants leads preferentially to hydrophobic surfaces, which may induce structural modification of confined proteins.

Time resolved fluorescence and anisotropy of fluorescence are powerful techniques for investigating structure and dynamics of 30 biological macromolecules. ${ }^{16,17}$ However these techniques are not frequently used to study the interactions between proteins and inorganic surfaces. ${ }^{18-21}$ The photophysical properties of aminoacids such as tryptophan (Trp) are indeed directly affected by their neighborhood. Investigations of the Trp fluorescence

35 lifetime provide access to fundamental aspects of the proteins structural modifications or protein/ligand interactions. In addition, fluorescence anisotropy, which is based on time dependence of the light depolarization emitted from a fluorophore, ${ }^{22,23}$ can be used to separate the contribution of the 40 entire macromolecule from local dynamic motions. ${ }^{24,25}$

The aim of this paper is to study the structure modification, orientation and stability of a hard model protein (Lysozyme) induced by its adsorption on different layered materials: sodium homoionic montmorillonite (Na-Mt), montmorillonite with non45 ionic surfactant tri-ethylene glycol mono n-decyl ether $\left(\mathrm{C}_{10} \mathrm{E}_{3}\right.$ $\mathrm{Mt}$ ), and LDH modified with sodium octylsulfate (SOS-LDH). Lysozyme is a small (MW $14.4 \mathrm{kDa}$ ) globular protein. Its crystallographic structure was the first to be established by X-ray diffraction (XRD) methods in $1965 .^{26}$ This discovery opened very 50 quickly the opportunity for researchers to correlate its known structure with its fluorescence properties and thus, nowadays its photophysical behavior is well known. ${ }^{27-30}$

\section{Materials and methods}

\section{Layered materials preparation}

55 The natural clay mineral, montmorillonite (Mt) extracted from the Crook county (Wyoming), was purchased from the Source Clays Repository (Clay mineral Society ref: Srce_Clay_SWy-2). Its cation exchange capacity (CEC) was reported to be about $75 \mathrm{meq} / 100 \mathrm{~g} .{ }^{31}$ The present work was carried out on clay mineral ${ }_{60}$ fraction $\leq 2 \mu \mathrm{m}$ obtained by dispersion, sedimentation and centrifugation. Cation exchanges were performed in salt solution, i.e. $1 \mathrm{M}$, made from pure $\mathrm{NaCl}$ (Sigma, 99,9\%) and de-ionized water. The sample (Na-Mt) preparation and elemental analysis are described in detail elsewhere. ${ }^{32}$

${ }_{65}$ The organo-Mt modified with nonionic surfactant was synthesized following the procedure of Guegan. ${ }^{33}$ A sodium homoionic Montmorillonite suspension was dispersed in a solution of nonionic surfactant tri-ethylene glycol mono n-decyl ether $\left(\mathrm{C}_{10} \mathrm{E}_{3}\right)$ (Nikko Chemicals, Inc., Tokyo, Japan) at a 70 concentration above its critical micelle concentration. ${ }^{34}$ In such a way, the resulting nonionic organo-Mt $\left(\mathrm{C}_{10} \mathrm{E}_{3}-\mathrm{Mt}\right)$ preserves $\mathrm{Na}^{+}$ cations in its interlayer space for further ion exchange, while 
showing a wide opening of the interlayer space $(2.6 \mathrm{~nm})$ due to the intercalation of a bilayer of $\mathrm{C}_{10} \mathrm{E}_{3}$.

SOS-LDH was obtained by intercalation of sodium octylsulfate (SOS), an anionic surfactant, (Sigma) inside calcined ${ }_{5} \mathrm{Mg}_{4} \mathrm{Al}_{2}(\mathrm{OH})_{12} \mathrm{CO}_{3} \cdot 3 \mathrm{H}_{2} \mathrm{O} \mathrm{LDH}$ (SüdChemieSyntal HSAC 701). The layered structure of the calcined material was reorganized in a solution of SOS at a concentration of 1 Anion Exchange 15

Table 1 Characteristics of the layered materials

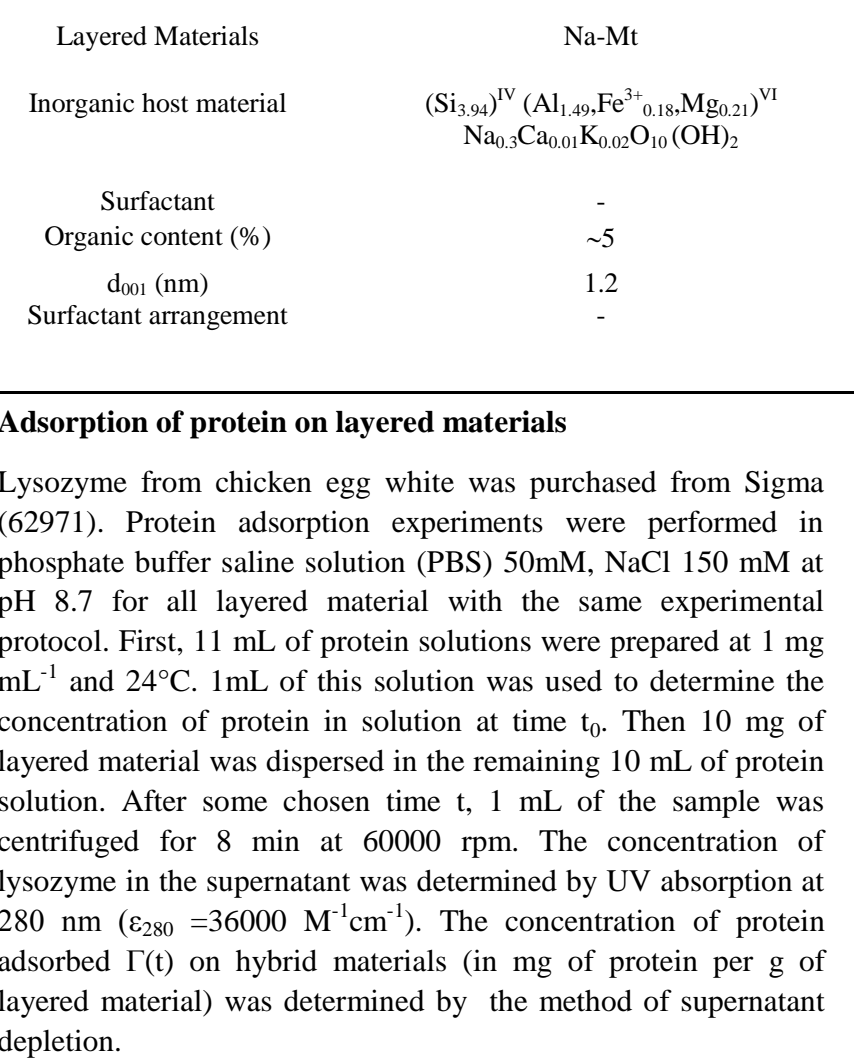

$\Gamma_{(\mathrm{t})}=\frac{\mathrm{v}\left(\mathrm{C}_{(0)}-\mathrm{C}_{(\mathrm{t})}\right)}{\mathrm{m}}$

Where $\mathrm{V}$ is the volume of the protein solution $(\mathrm{mL}), \mathrm{C}_{(0)}\left(\mathrm{mg} \mathrm{mL}^{-}\right.$ $\left.{ }^{1}\right)$ is the initial concentration of protein, $\mathrm{C}_{(\mathrm{t})}\left(\mathrm{mg} \mathrm{mL}^{-1}\right)$ is the supernatant protein concentration at time $t$, and $\mathrm{m}$ is the mass of the hybrid layered materials $(\mathrm{g})$.

\section{Fourier transform infrared spectroscopy (FTIR)}

FTIR spectra, in the range $650-4000 \mathrm{~cm}^{-1}$, were recorded using a Thermo Nicolet 6700 FT spectrometer equipped with a Deuterated Triglycine Sulfate (DTGS) detector and a Nicolet Continu $\mu \mathrm{m}$ microscocope. The powder samples were spread over an $\mathrm{NaCl}$ window of the microscope. The analyzed sample area was a square of side $100 \mu \mathrm{m}$ chosen under the microscope $15 \mathrm{X}$ Infinity Reflechromat objective. The analyses were performed in transmission mode and each spectrum was the average of 128 scans collected at $2 \mathrm{~cm}^{-1}$ resolution. FTIR was performed on dry samples $\left(25^{\circ} \mathrm{C}\right.$ under vaccum 2 hours).

\section{X-ray Diffraction (XRD)}

XRD patterns of hybrid layered materials were measured using capacity. The synthetic SOS-LDH displays a hydrophobic surface and a bilayer arrangement of the anionic SOS surfactant in the 10 internal structure of $\mathrm{Mg} / \mathrm{Al} \mathrm{LDH}$.

Both organo modified layered materials show a hydrophobic surface and a wide opening of their interlayer space. The detailed characteristics such as basal spacing of these host materials are reported in Table 1. an ARL X'TRA Diffractometer (Thermo Electron Corporation, Ecublens, Switzerland) equipped with a $\mathrm{Cu}$ anode and an Si solid detector operating at $40 \mathrm{kV}$ and $40 \mathrm{~mA}$. Experimental measurements were carried out at room temperature at $10 \mathrm{~s}$ counting time per $0.05^{\circ}(2 \theta)$ step. XRD was performed on dry sample $\left(25^{\circ} \mathrm{C}\right.$ under vaccum 2 hours $)$ such as FTIR experiments.

\section{UV absorbance and Fluorescence emission spectra}

UV absorbance spectra were recorded on a JASCO V-570 UVVis spectrophotometer at scanning rate $1 \mathrm{~nm} \mathrm{~s}^{-1}$. All solutions were filtered on a low protein binding Durapore ${ }^{\circledR}$ membrane (Millex-HV $0.45 \mu \mathrm{m}$ PDMF) to limit the light scattering due to clay microparticles. Moreover, filters were previously flushed with a protein solution to limit the error due to non specific protein adsorption on the filter.

\section{Time-resolved fluorescence}

Time-resolved fluorescence data were obtained by the timecorrelated single-photon counting technique. ${ }^{24,35}$ The excitation wavelength was achieved by using an $82 \mathrm{MHz}$ mode-locked argon ion laser (Spectra Physics model 2030) pumping synchronously a cavity-dumped rhodamine 6G dye laser (Spectra Physics model 375 dye laser and 344 cavity dumper). The UV excitation light, set to vertical polarization, was obtained using a frequency doubler (Spectra Physics 320). The excitation pulse duration was estimated at about 20 ps (full-width-at-halfmaximum, FWHM). The emission of fluorescence was detected, after passing through a polarizer set parallel, perpendicular or magic angle $\left(54.73^{\circ}\right)$ relative to vertical excitation, through a double monochromator Jobin-Yvon DH10 on a Hamamatsu H5323 photomultiplier (Cathode S20, TTS 160 ps). The instrumental response function of the equipment was measured by using a dilute suspension of polystyrene nanospheres in water (70 nm diameter) as a scattering solution; it was typically 220250 ps FWHM. Decays were collected at a maximum count rate of $15 \mathrm{kHz}$ into 2048 channels. This limiting count rate was achieved by dilution of the sample in order to minimize as much as possible the scattering of the particles and after sedimentation of the suspension. The time per channel was set around $18 \mathrm{ps} . \mathrm{ch}^{-1}$ 
in order to have a full decay in the experimental time window. All decays were collected in order to have at least $1.5 \times 10^{6}$ counts in total. The excitation wavelength was set at $294 \mathrm{~nm}$ and the collected emission at $345 \mathrm{~nm}$ for all samples.

Decay analysis was performed using a Levenberg-Marquardt algorithm. ${ }^{36}$ For the analysis the fluorescence decay law at the magic angle $I_{M}(t)$ and the anisotropy decay law $r(t)$ were analyzed as a sum of exponentials :

$$
\begin{aligned}
& \mathrm{I}_{\mathrm{M}}(\mathrm{t})=\frac{1}{3} \sum_{\mathrm{i}=1}^{\mathrm{n}} \alpha_{\mathrm{i}} \mathrm{e}^{-\mathrm{t} / \tau_{\mathrm{i}}} \\
& \mathrm{r}(\mathrm{t})=\sum_{\mathrm{j}=1}^{\mathrm{n}} \mathrm{r}_{\mathrm{j}} \mathrm{e}^{-\mathrm{t} / \phi_{j}}
\end{aligned}
$$

With $\tau_{\mathrm{i}}$ the fluorescence lifetime, $\alpha_{\mathrm{i}}$ the pre-exponential factor related to the contribution of each lifetime of component $i, r_{j}$ the anisotropy of a component $j$ for a correlation time $\phi_{\mathrm{j}}$.

The anisotropy decay, $\mathrm{r}(\mathrm{t})$ is related to the decays collected with vertical, $I_{V}(t)$, and horizontal, $I_{H}(t)$, polarization, the excitation being vertical:

$$
\begin{aligned}
& \mathrm{I}_{\mathrm{V}}(\mathrm{t})=\mathrm{I}_{\mathrm{M}}(\mathrm{t})\{1+2 \mathrm{r}(\mathrm{t})\} \\
& \mathrm{I}_{\mathrm{H}}(\mathrm{t})=\mathrm{I}_{\mathrm{M}}(\mathrm{t})\{1-\mathrm{r}(\mathrm{t})\}
\end{aligned}
$$

or

$$
r(t)=\frac{I_{V}(t)-I_{H}(t)}{I_{V}(t)+2 I_{H}(t)}
$$

Fluorescence lifetimes were calculated from data collected at magic angle by iterative adjustment after convolution ${ }^{37}$ of a pump profile (scattered light) with a sum of exponentials. The anisotropy decay function was determined using the parameters obtained from the analysis of the magic angle decay and simultaneous adjustment of vertical and horizontal data. ${ }^{24} \mathrm{We}$ assumed a Poisson distribution of counts in the calculation of the $\chi^{2}$ criterion; residuals profiles and autocorrelation function as well as Durbin-Watson and skewness factor, ${ }^{38-40}$ were used in order to estimate the quality of the adjustment. The number of exponentials used for the fit was increased until all the statistical criterions were improved. In order to enhance the fit of the whole decay, the shift that experimentally occurs between the pump profile and the decay was also introduced as a fitting parameter. After adjustment and as a control, the anisotropy decay functions $\mathrm{r}(\mathrm{t})$ calculated from the experimental data and from the extracted parameters were displayed.

Fluorescence experiment was performed phosphate buffer saline solution (PBS) 50mM, $\mathrm{NaCl} 150 \mathrm{mM}$ at $\mathrm{pH} 8.7$.

\section{Results and discussion}

\section{Protein adsorption}

The adsorption of lysozyme was performed below its isoelectric point (IP $=10.7$ ) at $\mathrm{pH} 8.7$. Under these conditions, the protein is globally positively charged. ${ }^{41,42}$ The kinetics of lysozyme adsorption on different layered materials are depicted in Fig. 1. As expected, the kinetics of lysozyme adsorption are fast on $\mathrm{Na}$ Mt. Indeed, this clay mineral is globally negatively charged with exchangeable cations within the interlayer space. Furthermore, the equilibrium state is reached after $90 \mathrm{~min}$ and the amount of loaded protein reaches $\Gamma_{\text {lys }}=791 \mathrm{mg} / \mathrm{g}_{\mathrm{Na}-\mathrm{Mt}}$. Electrostatic interactions between the positively charged lysozyme and the negatively charged clay mineral occurred and resulted in an exchange with the inorganic interlayer cations. ${ }^{43}$.

After intercalation of $\mathrm{C}_{10} \mathrm{E}_{3}$ nonionic surfactant, the hydrophobic character of the clay mineral increases. The concentration of adsorbed lysozyme on $\mathrm{C}_{10} \mathrm{E}_{3}-\mathrm{Mt}$ after $450 \mathrm{~min}$ is $550 \mathrm{mg} / \mathrm{g}_{\mathrm{C} 10 \mathrm{E} 3-\mathrm{Mt}}$ without reaching equilibrium as for SOS-LDH $\left(300 \mathrm{mg} / \mathrm{g}_{\text {SOS-LDH }}\right.$ at $450 \mathrm{~min}$ )

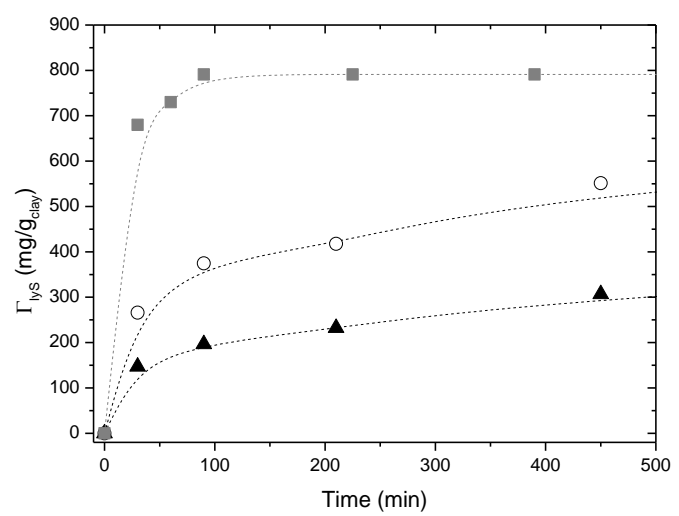

Fig. 1: Kinetics of Lysozyme adsorption at $\mathrm{pH} 8.7$ on Na-Mt (gray square), $\mathrm{C}_{10} \mathrm{E}_{3}-\mathrm{Mt}$ (open circle) and SOS-LDH (b) (black triangle)

\section{Protein localization in layered materials in dry state.}

Intercalation of lysozyme into the interlayer space of Na-Mt and $\mathrm{C}_{10} \mathrm{E}_{3}$-Mt was characterized by using powder X-ray diffraction. The XRD patterns exhibit an increase of the (001) basal spacing from 1.2 to $5.4 \mathrm{~nm}$ and from 3.6 to $4.6 \mathrm{~nm}$ for the Na-Mt and $\mathrm{C}_{10} \mathrm{E}_{3}-\mathrm{Mt}$, respectively (Fig. 2). These increases after intercalation are compatible with the dimension of the lysozyme $\left(4.5 \times 3 \times 3 \mathrm{~nm}^{3}{ }^{44}\right)$ and suggest a complete insertion of the protein within the interlayer space. In addition a difference of basal spacing $0.8 \mathrm{~nm}$ between both layered materials is observed. The adsorption of lysozyme on $\mathrm{Na}-\mathrm{Mt}$ and $\mathrm{C}_{10} \mathrm{E}_{3}$-Mt involves cation exchange with the sodium counter ions, with complete insertion of the protein within the interlayer space. The adsorption of lysozyme on $\mathrm{C}_{10} \mathrm{E}_{3}-\mathrm{Mt}$ is partly driven by electrostatic interactions as for Na-Mt. In addition to these electrostatic interactions, the protein polar residues interact with the $\mathrm{C}_{10} \mathrm{E}_{3}$-Mt hydrophobic surface. The slower and lower lysozyme adsorption on $\mathrm{C}_{10} \mathrm{E}_{3}$-Mt than on $\mathrm{Na}-\mathrm{Mt}$ may be explained by the previous intercalation of $\mathrm{C}_{10} \mathrm{E}_{3}$ surfactant within the interlayer space which hinders the access to the interaction sites and limits the accessible surface.

On the contrary, the X-ray diffraction patterns (not shown) for the SOS-LDH did not display any particular differences with or without protein; the $(00 l)$ reflections remained at a similar $2 \theta$ angle; this suggest that the adsorption is only occurring on the external surface of the particles. This result is not surprising since no cation exchange can occur between the positively charged protein and the LDH. Indeed, the SOS-LDH is characterized by a hydrophobic surface and a weak anionic exchange capacity since carbonate can easily be re-intercalated. In this case, the adsorption process may not be driven by the electrostatic interactions. Indeed, the positively charged protein can only be 
adsorbed on the external surface of the SOS-LDH and cannot be exchanged with the carbonates located in the interlayer space.

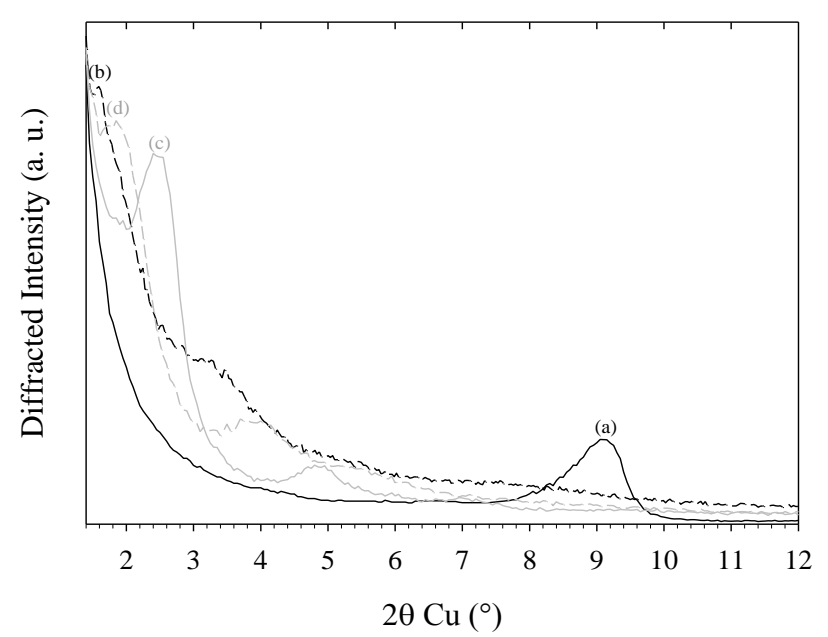

Fig. 2 : XRD patterns for (a) Na-Mt in black line, (b) Na-Mt with lysozyme in black dash line, (c) $\mathrm{C}_{10} \mathrm{E}_{3}$-Mt synthesized by using $\mathrm{C}_{10} \mathrm{E}_{3}$ surfactant in gray line and (d) $\mathrm{C}_{10} \mathrm{E}_{3}$-Mt with lysozyme in gray dash line. Large peaks for the layered materials without lysozyme (a), (c) and with lysozyme (b), (d) correspond to $\mathrm{d}_{001}$ reflections at 1.2 or $3.6 \mathrm{~nm}$, and at 5.4 and $4.6 \mathrm{~nm}$.

\section{Stability of lysozyme in layered materials in dry state.}

The confinement of proteins into the interlayer space of lamellar materials can induce an increase in their stability. One consequence can be that they keep their conformational structure even under lack of water. ${ }^{45}$ FTIR is a powerful technique for the determination of the conformational changes of proteins in interaction with surfaces. ${ }^{46,47}$ Indeed it is sensitive to modification of ratio $\alpha$-helix versus $\beta$-sheet.

Infrared spectra of dry samples of lysozyme loaded on layered materials are reported in Fig. 3. The insert highlights the amide bands I and II of the peptide backbones. These bands are very sensitive to conformational changes of proteins and are used to probe their modification of structures. These carbonyl vibration modes in the amide bands I and II usually are observed for lysozyme in buffer solution at 1600 and $1525 \mathrm{~cm}^{-1}$, respectively. For intercalated lysozyme in $\mathrm{Na}-\mathrm{Mt}$ and $\mathrm{C}_{10} \mathrm{E}_{3}-\mathrm{Mt}$, these vibration modes remained at the same frequency which means a constant ratio $\alpha$-helix versus $\beta$-sheet with respect to solution.
These results suggest that no strong conformational change is occurring when the water is removed. This stabilization of the structure of the protein is induced by the confinement. Indeed, hard proteins are often stabilized when they are confined in porous materials. ${ }^{48}$ Thus it can be assumed that lysozyme almost keeps its geometry, even if small conformational changes cannot be dismissed. Regarding XRD experiments (Fig 2), which are performed under same condition than FTIR, the difference of basal spacing $0.8 \mathrm{~nm}$ obtained in between Na-Mt and $\mathrm{C}_{10} \mathrm{E}_{3}-\mathrm{Mt}$ could be interpreted as the difference in between the model of "end-on" and "side-on" orientations (Fig. 4a and b). ${ }^{49}$ In contrast, the FTIR spectra of lysozyme adsorbed on external surface of SOS-LDH show noticeable shifts in frequencies (between 5 and $10 \mathrm{~cm}^{-1}$ ) for the peptide backbone vibration in the amide bands. This indicates a modification of the conformation of the adsorbed proteins. As previously discussed, lysozyme adsorption on the external surface (Fig 4c) of SOS-LDH does not seem to induce this unfolding. Thus the dehydration may induce partial structural changes of lysozyme because the protein is not protected inside the interlayer space.

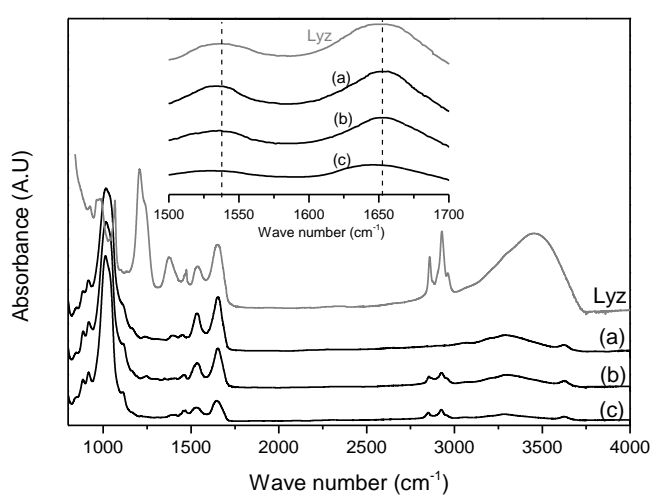

Fig. 3 Infrared spectra of lysozyme confined in (a) Na-Mt, (b) $\mathrm{C}_{10} \mathrm{E}_{3}-\mathrm{Mt}$, and (c) adsorbed on SOS-LDH particles obtained after dehydration compared to native lysozyme (Lyz). The insert represent a zoom of the lysozyme carbonyl vibration modes, associated with the peptide backbone vibration in the amide bands. 

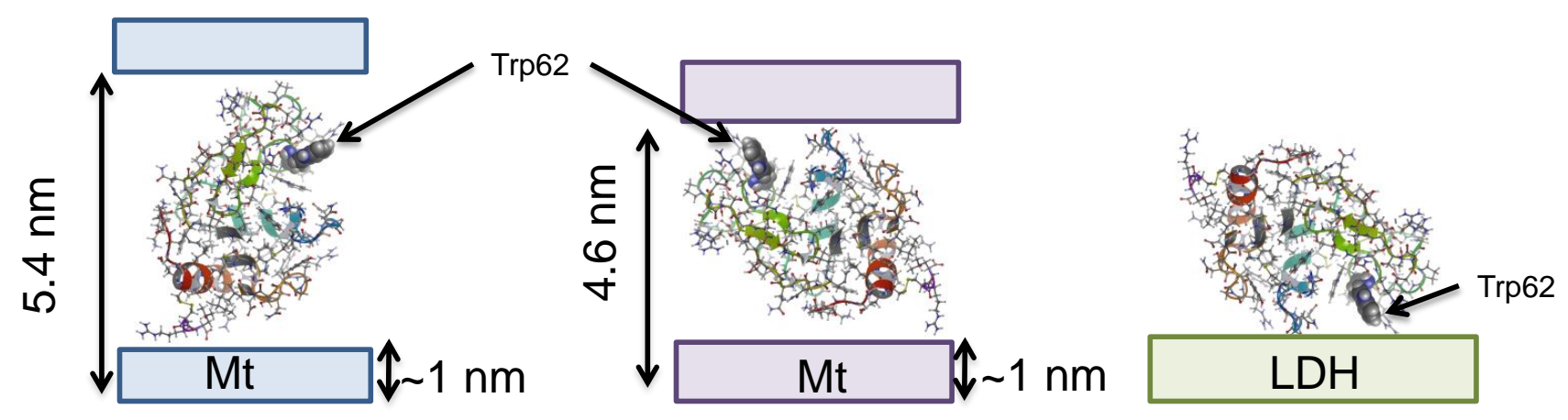

(a)

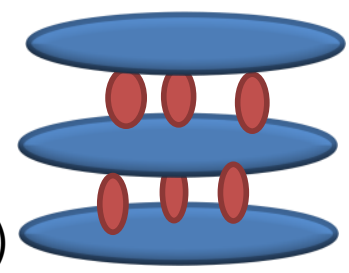

(b)

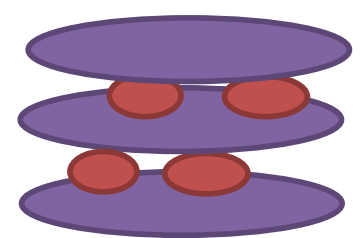

(c)

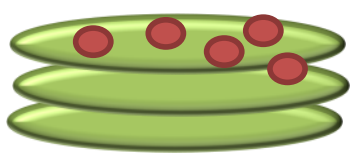

Fig. 4 Illustration of lysozyme confined in interlayer space of (a) Na-Mt with "end-on" orientation and (b) $\mathrm{C}_{10} \mathrm{E}_{3}$-Mt with "side-on" orientation or adsorbed on particle surface of (c) SOS-LDH.

Protein conformation and orientation in layered materials in 5 buffer suspension.

\section{Fluorescence properties of the lysozyme tryptophans: Background.}

The amino acid sequence of lysozyme contains six tryptophan residues; three of them are localized in the active site, Trp62 and

10 Trp63 on one side and Trp108 (Fig 5) on the opposite side of the ligand pocket, two others, Trp28 and Trp111, in the hydrophobic matrix region of the protein, the last Trp123 apart from all the others on the other side of the protein. Concerning the fluorescence properties of the protein, it has been shown that 15 Trp63 and Trp123 do not participate to the total emission of fluorescence; the presence in their neighborhood of disulphide linkages (Cys(76)-Cys(94) and Cys(6)-Cys(127) respectively) induces a quenching of their emission. ${ }^{28}$ Nishimoto et al, ${ }^{50,51}$ in a study of two mutants of lysozyme (W62Y and W108Y) where

20 Trp62 and Trp108 are respectively replaced by tyrosine residues, have resolved the emission spectrum of the whole protein in solution. They showed that the emission of the protein can be describe as two regions, one characteristic of a hydrophobic environment at short emission wavelength with Trp28 and 25 Trp111 (partially resolved) in the range $320-330 \mathrm{~nm}$, the other of a polar environment at longer wavelength with Trp62 and Trp108 at 352 and $342 \mathrm{~nm}$ respectively. In their study the contributions of $\operatorname{Trp} 28$ and Trp111 have been estimated to be $38 \%$ and $23 \%$ of the total emission for the W62Y and W108Y mutants respectively. 30 These results imply that at least $70 \%$ of the total emission in the wild type lysozyme is coming from Trp62 and Trp108. This proportion agrees with previous works where a contribution of 80 $\%$ was already estimated. ${ }^{27}$

In our experiments, the lysozyme conformation and orientation in 35 solution and in layered materials have been studied by following the time resolved fluorescence and anisotropy of fluorescence of the tryptophan residues. In all our experiments data were collected at $345 \mathrm{~nm}$. This emission wavelength was chosen far from the excitation wavelength in order to avoid problems of 40 scattering light and close enough from the maximum of emission in order to get a high count rate. At $345 \mathrm{~nm}$ the contributions of Trp62 and Trp108 are almost equal and can be estimated from Nishimoto et $\mathrm{al}^{50,51}$ to be around $92 \%$ of the total emission of the protein; the other $18 \%$ are contributions of $\operatorname{Trp} 28$ and $\operatorname{Trp} 111$, 45 which have a maximum emission at longer wavelength in the blue side of the spectrum. 

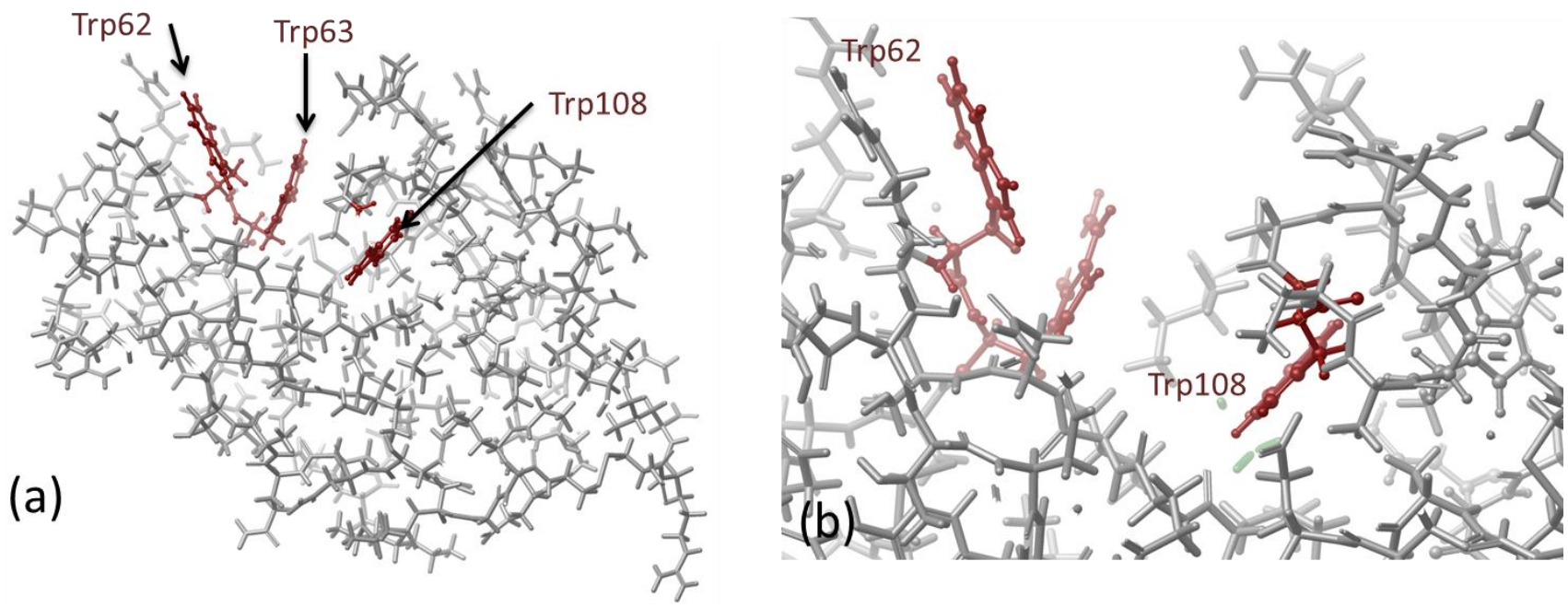

Fig. 5 Lysozyme structure (a) complete structure and (b) zoom on Trp62, Trp63 and Trp108

Lysozyme in buffer solution.

A typical experiment of time-resolved fluorescence and time5 resolved depolarization of lysozyme in solution is illustrated in Fig. 6. Results of the analysis are summarized in Table 2. Four fluorescence lifetimes has been necessary in order to describe adequately the decays of the lysozyme in solution. This multiexponential behavior is frequently observed even for proteins 10 with a single tryptophan; this can be explained by the complex photophysical properties of the indole chromophore. Two overlapping transition dipoles ${ }^{1} \mathrm{~L}_{\mathrm{a}}$ and ${ }^{1} \mathrm{~L}_{\mathrm{b}}$, nearly perpendicular to each other are involved in the absorption and emission process of the indole chromophore. The possibility of different rotamers in 15 the ground state and in these two nearly degenerate electronic states may explain the multi-exponential behavior of the fluorescence decay. ${ }^{29,52,53}$ During the analysis, the introduction of a fourth component was necessary in order to improve significantly the adjustment of the decays. This calculation has 20 led to the appearance of a short component of around $10 \mathrm{ps}$. As we used a double monochromator and are $50 \mathrm{~nm}$ away from the excitation wavelength, a contribution of scattering light can be rejected. The possibility of an artifact in the convolution process is also rejected since we did not observe similar behavior for 25 other molecules. Although even if this component is at the limit of our resolution, which means that, we cannot resolve it, we think we are still able to evidence it. A similar component with a maximum weight at shorter wavelength has already been observed; it was suggested by the authors to be a contribution of 30 Trp28 and Trp $111 .^{50}$ Apart from this short component three other fluorescence lifetimes, $3.79 \mathrm{~ns}, 1.78 \mathrm{~ns}$ and $0.62 \mathrm{~ns}$, were necessary in the analysis. The corresponding average lifetime is estimated to be $2.05 \mathrm{~ns}$. The anisotropy decay of the lysozyme in solution was best analyzed using two correlation times: $\phi_{1}=3.98$ $35 \mathrm{~ns}$ and $\phi_{2}=0.15 \mathrm{~ns}$. These results are in accordance with previous works. ${ }^{54,55}$

The expression of the anisotropy $\mathrm{r}(\mathrm{t})$ can be rewritten as :

$r(t)=\left[r_{T r p} e^{-t / \phi_{T r p}}+r_{P}\right] e^{-t / \phi_{P}}$

where $\phi_{\mathrm{P}}$ and $\phi_{\mathrm{Trp}}$ correspond respectively to the correlation 40 times for the global motion of the protein and to the local motion of the fluorophores inside the protein. The long component $\phi_{1}$, consistent with the rotational correlation time for the whole-body of lysozyme calculated by the Einstein-Stokes relationship, is associated to $\phi_{\mathrm{P}}$ and the short component $\phi_{2}$ related to the fast 45 depolarization motion $\phi_{\operatorname{Trp}}$ of the tryptophans inside the protein. Using $\phi_{1}$ and assuming a spherical geometry for the protein, the hydrodynamic volume of the lysozyme has been estimated to $1.6910^{-26} \mathrm{~m}^{3}$ (hydrodynamic diameter $3.2 \mathrm{~nm}$ ), which is in agreement with previously reported values. ${ }^{54,55}$

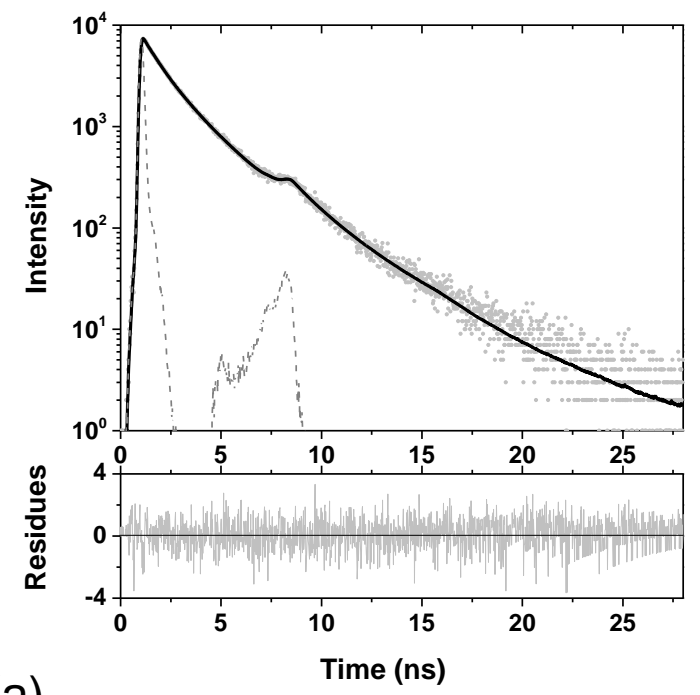

(a) 


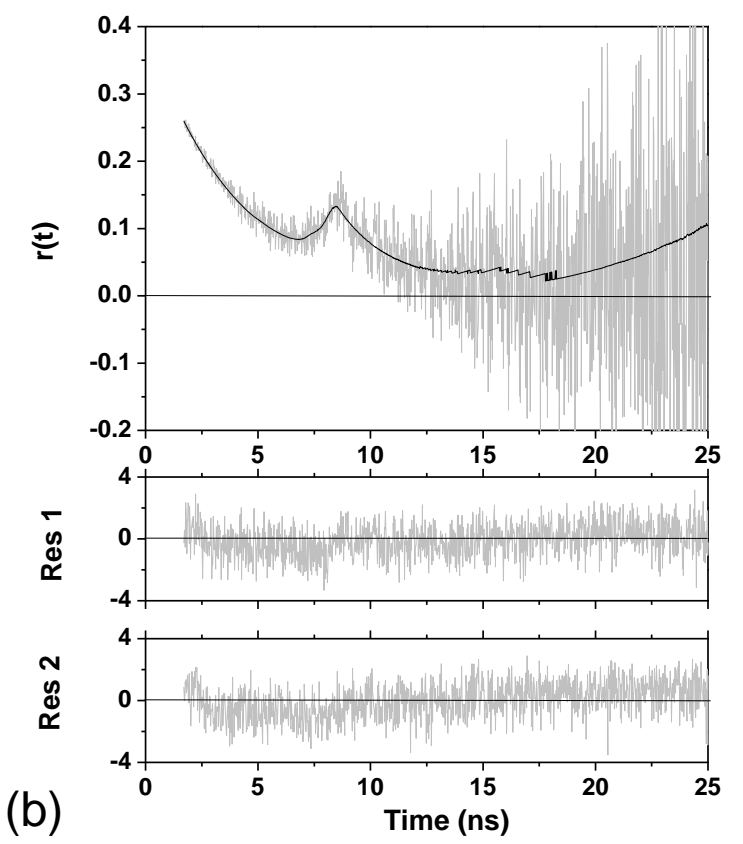

Fig. 6 (a) fluorescence decay and (b) anisotropy decay of lysozyme in buffer solution (res 1 and res 2 are residues function of fit $I_{V}(t), I_{H}(t)$, respectively)

The intrinsic anisotropy $r_{(0)}$ is a function of the relative orientations of the absorption and emission transition dipole moments. Its maximum and minimum values are 0.4 and -0.2 , which are reached when both absorption and emission transition 10 dipoles are parallel or perpendicular, respectively. The absorption of the tryptophan originates from two transition dipoles, ${ }^{1} \mathrm{~L}_{\mathrm{a}}$ and ${ }^{1} \mathrm{~L}_{\mathrm{b}}$, which are nearly perpendicular to each other with different initial anisotropy $\left(0.33,-0.165\right.$ respectively) ${ }^{56}$ the resulting global depolarization $r_{(0)}$ being an average value of these two 15 contributions. Recent studies show that ultrafast internal conversion (80-150 fs) occurs between these two electronic states as well as solvation dynamics from the environment (picosecond scale for proteins). ${ }^{57}$ Resonance energy transfer has been demonstrated to occur in the same ultrafast range. ${ }^{57,58}$ All these 20 ultrafast phenomena contribute to decrease the observable initial anisotropy $r_{(0)}$ at the available fluorescence timescale.

For the lysozyme in solution we found $r_{(0)}=0.25\left(r_{1}+r_{2}\right)$ which is in agreement with usual values using similar techniques. ${ }^{54,55}$

\section{Lysozyme loaded on layered materials}

As for the lysozyme in solution, a four lifetime adjustment was necessary for the layered materials. The analysis for the lysozyme incorporated in $\mathrm{Na}-\mathrm{Mt}$ and $\mathrm{C}_{10} \mathrm{E}_{3}-\mathrm{Mt}$ (Table 2) show a slight

30 decrease with respect to the lysozyme in solution for most lifetimes except the longer one; the average fluorescence lifetime decreases, $1.77 \mathrm{~ns}$ and $1.89 \mathrm{~ns}$ for $\mathrm{Na}-\mathrm{Mt}$ and $\mathrm{C}_{10} \mathrm{E}_{3}-\mathrm{Mt}$ respectively. On the contrary, lifetimes and average lifetime (2.11 ns) for the SOS-LDH remain almost similar to those of the 35 lysozyme in buffer. The emission spectra of the suspension of all the adsorbed samples have been recorded; they remain identical to the one of the protein in solution (not shown). As the emission spectrum of the fully denatured protein is known to exhibit a red shift of about $14 \mathrm{~nm},{ }^{30}$ which is not evidenced for any of our 40 samples, a denaturation of the adsorbed protein is very unlikely. This result is in accordance with the known "hard protein behavior" of the lysozyme. The decrease of the average lifetime for the Na-Mt and $\mathrm{C}_{10} \mathrm{E}_{3}$-Mt samples is in agreement with a modification of the polarity of the surrounding medium of the 45 tryptophans observed at $345 \mathrm{~nm}$. This can be correlated to the confinement of the protein in the interlayer space of the material as already suggested by the XRD experiments. On the contrary, the unchanged average lifetime for the SOS-LDH suggests a different behavior for this sample. This different behavior was 50 already shown in the XRD experiments where no intercalation was evidenced. Anisotropy decays of lysozyme adsorbed on $\mathrm{Na}-$ Mt, $\mathrm{C}_{10} \mathrm{E}_{3}$-Mt and SOS-LDH are presented in Fig. 7. Data for lysozyme confined in Na-Mt and $\mathrm{C}_{10} \mathrm{E}_{3}$-Mt can be fitted with two correlation times (Table 2) i) a long one around $40 \mathrm{~ns}$ ii) and a 55 shorter one of 0.18 and $0.31 \mathrm{~ns}$, respectively. For the lysozyme loaded on SOS-LDH, only one correlation time of $48 \mathrm{~ns}$ was needed. No correlation time around $4 \mathrm{~ns}$, which is characteristic of the free lysozyme in solution, has been revealed by the analysis; this suggests that the adsorption process is probably 60 complete and irreversible for all samples. The uncertainty in the determination of very long correlation times is very high in time resolved anisotropy experiments since the observation time window $(\approx 37 \mathrm{~ns}$ in these experiments) is limited by the fluorescence lifetime of the sample. 
Table 2 Fluorescence lifetime $\left(\tau_{\mathrm{i}}\right)$, anisotropy correlation time $\left(\phi_{\mathrm{i}}\right)$ and depolarization component $(\mathrm{rj})$ results for lysozyme in buffer solution and loading on layered materials obtained for excitation wavelength $294 \mathrm{~nm}$ and recorded at $345 \mathrm{~nm} . \mathrm{Y}_{\mathrm{i}}=100 \alpha_{\mathrm{i}} \tau_{\mathrm{i}} / \sum \alpha_{\mathrm{i}} \tau_{\mathrm{i}}$ represents the contribution of each emission to the total emission.

$\begin{array}{ccccccccccc} & \tau_{1}(\mathrm{~ns}) & \tau_{2}(\mathrm{~ns}) & \tau_{3}(\mathrm{~ns}) & \tau_{4}(\mathrm{~ns}) & \mathrm{Y}_{1}(\%) & \mathrm{Y}_{2}(\%) & \mathrm{Y}_{3}(\quad) & \mathrm{Y}_{4}(\%) & <\tau>(\mathrm{ns}) & \chi^{2} \\ \text { Buffer } & 3.79 & .78 & 0.62 & 0.01 & 23 & 60 & 4 & 3 & 2.05 & 0.98 \\ \mathrm{Na}-\mathrm{Mt} & 4.06 & 1.42 & 0.4 & 0.01 & 24 & 50 & 21 & 5 & 1.77 & 1 \\ \mathrm{C}_{10} \mathrm{E}_{3}-\mathrm{Mt} & 3.87 & 1.41 & 0.39 & 0.02 & 30 & 47 & 18 & 6 & 1.89 & 1.1 \\ \text { SOS- LDH } & 4.83 & 1.72 & 0.51 & 0.01 & 27 & 47 & 19 & 6 & 2.11 & 1.1 \\ & \varphi_{1}(\mathrm{~ns}) & \varphi_{2}(\mathrm{~ns}) & \mathrm{r}_{1} & \mathrm{r}_{2} & \mathrm{r}_{(0)} & \chi_{\mathrm{v}}^{2} & \chi_{\mathrm{h}}^{2} & & & \\ \text { Buffer } & 3.98 & 0.15 & 0.23 & 0.02 & 0.25 & 0.98 & 1.1 & & & \\ \mathrm{Na}-\mathrm{Mt} & 4 & 0.18 & 0.15 & 0.02 & 0.17 & 1.1 & 1 & & & \\ \mathrm{C}_{10} \mathrm{E}_{3}-\mathrm{Mt} & 40 & 0.31 & 0.14 & 0.02 & 0.16 & 1.1 & 1.1 & & & \\ \text { SOS- LDH } & 48 & - & 0.12 & - & 0.12 & 1.1 & 1.1 & & \end{array}$

The correlation times around $40 \mathrm{~ns}$ are probably under estimated; 5 they are associated to the global rotation of the whole entity "protein-material".

The second correlation time and its amplitude of depolarization for the lysozyme loaded on Na-Mt $\left(\phi_{2}=0.18 \mathrm{~ns}, \mathrm{r}_{2}=0.02\right)$ are very similar to those in the buffer solution $\left(\phi_{2}=0.15 \mathrm{~ns}, \mathrm{r}_{2}=\right.$ 10 0.02); for the $\mathrm{C}_{10} \mathrm{E}_{3}-\mathrm{Mt}$ sample, results are also very similar, with a slight increase of $\phi_{2}\left(\phi_{2}=0.31 \mathrm{~ns}, \mathrm{r}_{2}=0.02\right)$. These results suggest that the observed tryptophan at $345 \mathrm{~nm}$ have a similar behavior in lysozyme adsorbed on Na-Mt than in solution; the protein located in the interlayer space is surrounded by a medium 15 of lower polarity and its structure remains mainly unchanged. In the interlayer space, the protein is still hydrated. As the ${ }^{1} \mathrm{~L}_{\mathrm{a}}$ transition is more sensitive to solvation than the ${ }^{1} \mathrm{~L}_{\mathrm{b}}$ transition, any modification of polarity will induce a modification in the average value of the initial anisotropy $r_{(0)} .{ }^{58}$ This effect as well as 20 other ultrafast processes involving the surrounding medium, as mentioned before, could be responsible for the lower value of $r_{(0)}=0.17$ observed for the Na-Mt sample. A same behavior is observed for the $\mathrm{C}_{10} \mathrm{E}_{3}$-Mt sample where the initial anisotropy $r_{(0)}$ decreases to 0.16 . The data for the lysozyme adsorbed on ${ }_{25} \mathrm{C}_{10} \mathrm{E}_{3}$-Mt present a slower motion of a similar amplitude $\left(\phi_{2}=\right.$ $0.31 \mathrm{~ns}, \mathrm{r}_{2}=0.02$ ) comparatively to the sample loaded on $\mathrm{Na}-\mathrm{Mt}$ or in solution. The protein located in the interlayer space is as before surrounded by a medium of lower polarity (the lifetimes are shorter) with a possible steric obstruction due to the presence 30 of nonionic surfactant $\left(\mathrm{C}_{10} \mathrm{E}_{3}\right)$ or a stronger interaction with the surface of the material than in the case of sample Na-Mt. From Nishimoto et $\mathrm{al}^{50,51}$ it is known that Trp62, in the lysozyme in solution, has a higher degree of freedom and is more exposed to the bulk water than Trp108 (Fig. 5). From this result, the increase 35 of the shorter correlation time $\phi_{2}$ may be interpreted as a decrease of the mobility of Trp62. This behaviour suggests a stronger interaction in the neighbourhood of Trp62 in the $\mathrm{C}_{10} \mathrm{E}_{3}-\mathrm{Mt}$ sample than in the Na-Mt sample. As the results for the Na-Mt and the $\mathrm{C}_{10} \mathrm{E}_{3}-\mathrm{Mt}$ samples in suspension are very similar 40 (lifetimes, yields, average lifetimes, emission spectra) apart for this small difference in the internal correlation time $\phi_{2}$ it is reasonable to think that the structures of the lysozyme in both cases are very similar and that the main difference between the two samples is the position of the protein in the interlayer. These 45 observations are compatible with an orientation "side-on", which was already suggested by the interlayer space determined in XRD experiments, where the Trp62 is expected to be in a higher interaction with the material in the $\mathrm{C}_{10} \mathrm{E}_{3}$-Mt sample. For the NaMt sample, where the shorter correlation time is almost identical 50 to the one in solution, which means not perturbed by its environment, an orientation "end-on" is more adequate.

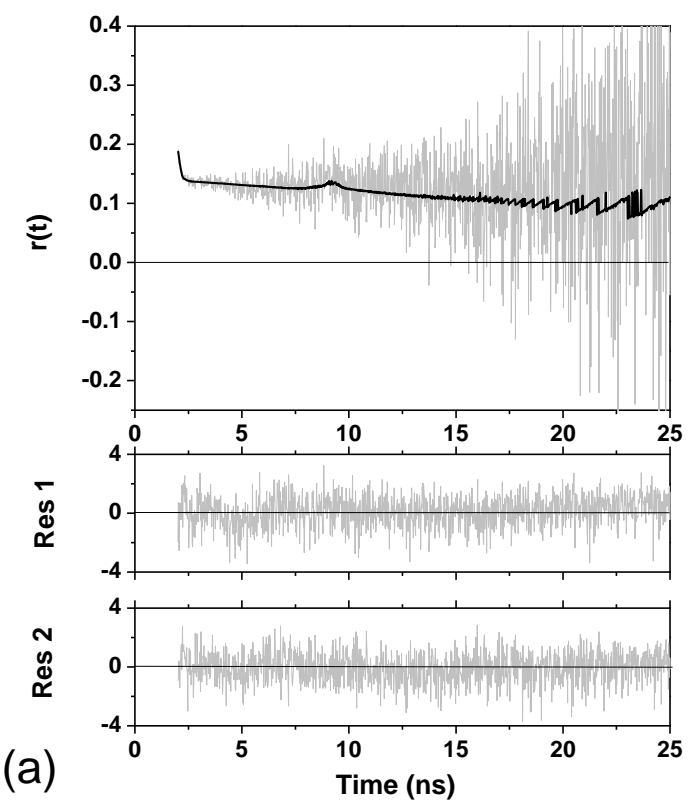



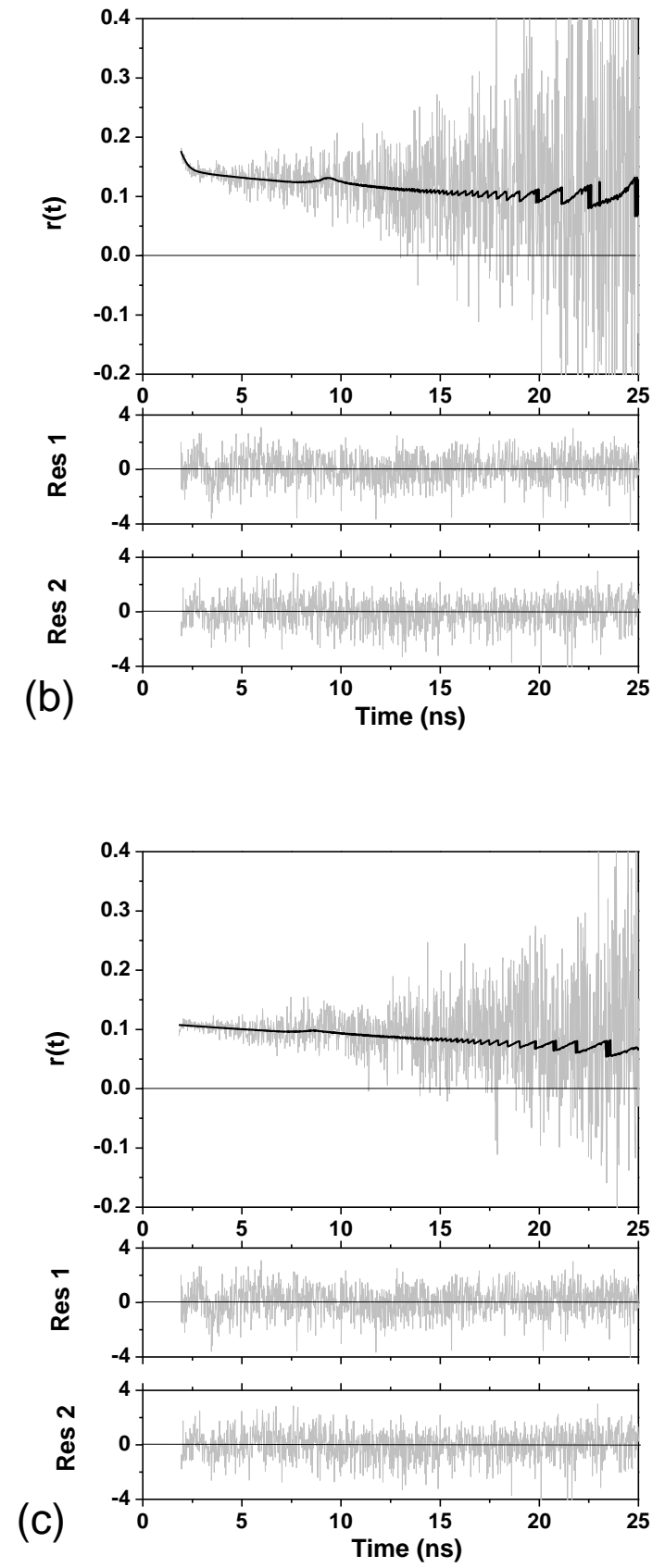

Fig.7 anisotropy decay of lysozyme loaded on (a) Na-Mt, (b) $\mathrm{C}_{10} \mathrm{E}_{3}-\mathrm{Mt}$ 5 and (c) SOS-LDH (res 1 and res 2 are residues function of fit $I_{V}(t), I_{H}(t)$ , respectively)

For lysozyme loaded on SOS-LDH, the lack of the short correlation time suggests a loss of the motion of the tryptophans observed at $345 \mathrm{~nm}$. As both lifetimes (and average lifetime) and 10 emission spectrum are very similar to those of the protein in solution, a denaturation of the protein can probably be rejected. The low value of $r_{(0)}=0.12$ obtained from the anisotropy measurements suggests a strong modification of the neighborhood of the tryptophans. According to the XRD 15 experiment, where it was shown that the lysozyme cannot be intercalated inside the interlayer space, a possible adsorption of the lysozyme on SOS-LDH, with an orientation of the protein compatible with an interaction of the tryptophan with the surface is suggested. Such a model is illustrated in Fig. 3c.

\section{${ }_{20}$ Conclusion}

Lysozyme adsorption was studied on three different layered materials: Na-Mt, $\mathrm{C}_{10} \mathrm{E}_{3}$-Mt and SOS-LHD. For all materials the adsorption process does not induce large structural changes of the protein. It was shown that the protein is confined inside the 25 interlayer space of $\mathrm{Na}-\mathrm{Mt}$ and $\mathrm{C}_{10} \mathrm{E}_{3}$-Mt with a possible "end-on" and "side-on" orientations, respectively. On the contrary, for SOS-LDH the protein is located on the surface of particles since no cation exchange can occur due to the positive charge of LDH. After dehydration, strong structural changes have only been 30 observed for protein adsorbed on the surface of particles of SOSLHD.

\section{Notes and references}

${ }^{a}$ Institut Européen des Membranes, UMR5635 CNRS-UM2-ENSCM Université Montpellier 2, Place Eugene Bataillon, 34095 Montpellier 35 cedex 5 , France:

${ }^{b}$ Institut Charles Gerhardt UMR 5253 CNRS, Université Montpellier 2,

Place Eugene Bataillon, 34095 Montpellier cedex 5, France

${ }^{c}$ Institut des Sciences de la Terre d'Orléans, UMR 7327 CNRS-Université d'Orléans, 1 A Rue de la Férolerie, 45071 Orléans Cedex 2, France

${ }_{40}{ }^{d}$ Laboratoire de Réactivité de Surface, UMR 7197, UPMC Univ Paris 06 and CNRS, Case Courrier 178, 3, Rue Galilée, F-94200 Ivry-sur-Seine,

France

* to whom correspondence should be addressed at Sebastien Balme : 45 sebastien.balme@iemm.univ-montp2.fr, tel:+33467149118 or Regis Guégan regis.guegan@univ-orleans.fr, tel: +33238492541

1 A. J. Patil; E. Muthusamy; S. Mann, Angew Chem Int Edit, 2004, 43, 4928-4933.

502 L. M. Liu; B. Shen; J. J. Shi; F. Liu; G. Y. Lu; J. J. Zhu, Biosens Bioelectron, 2010, 25, 2627-2632.

3 C. V. Kumar; A. Chaudhari, Chem Commun, 2002, 2382-2383.

4 T. Coradin; A. Coupe; J. Livage, J Mater Chem, 2003, 13, 705-707.

5 A. J. Patil; S. Mann, J Mater Chem, 2008, 18, 4605-4615.

556 A. J. Patil; E. Muthusamy; S. Mann, J Mater Chem, 2005, 15, 38383843.

7 A. J. Patil; M. Li; E. Dujardin; S. Mann, Nano Lett, 2007, 7, 26602665.

8 C. V. Kumar; A. Chaudhari, J Am Chem Soc, 2000, 122, 830-837.

609 Q. Y. Lu; F. Gao; S. Komarneni; T. E. Mallouk, J Am Chem Soc, 2004, 126, 8650-8651.

10 M. Jaber; M. Bouchoucha; L. Delmotte; C. Methivier; J. F. Lambert, $J$ Phys Chem C, 2011, 115, 19216-19225.

11 M. Jaber; J. F. Lambert, J Phys Chem Lett, 2010, 1, 85-88.

6512 A. Vinu; V. Murugesan; M. Hartmann, J Phys Chem B, 2004, 108, 7323-7330.

13 R. Guegan; D. Morineau; R. Lefort; W. Beziel; M. Guendouz; L. Noirez; A. Henschel; P. Huber, Eur Phys J E, 2008, 26, 261-273.

14 R. Guegan; D. Morineau; C. Alba-Simionesco, Chem Phys, 2005, 70 317, 236-244.

15 L. C. Sang; A. Vinu; M. O. Coppens, Langmuir, 2011, 27, 1382813837. 
16 D. P. Millar, Curr Opin Struc Biol, 1996, 6, 637-642.

17 D. Anunciado; M. Agumeh; B. L. Kormos; D. L. Beveridge; J. L. Knee; A. M. Baranger, J Phys Chem B, 2008, 112, 6122-6130.

18 K. Nakanishi; T. Sakiyama; K. Imamura, J Biosci Bioeng, 2001, 91, 5 233-244.

19 S. Balme; J. M. Janot; P. Dejardin; E. N. Vasina; P. Seta, J Membrane Sci, 2006, 284, 198-204.

20 C. Rocker; M. Potzl; F. Zhang; W. J. Parak; G. U. Nienhaus, Nat Nanotechnol, 2009, 4, 577-580.

1021 H. Fukumura; K. Hayashi, J Colloid Interf Sci, 1990, 135, 435-442.

22 C. N. Bialik; B. Wolf; E. L. Rachofsky; J. B. A. Ross; W. R. Laws, Biophys J, 1998, 75, 2564-2573.

23 E. Feinstein; G. Deikus; E. Rusinova; E. L. Rachofsky; J. B. A. Ross; W. R. Laws, Biophys J, 2003, 84, 599-611.

1524 S. Balme; J. M. Janot; P. Dejardin; P. Seta, J Photoch Photobio A, 2006, 184, 204-211.

25 J. R. Lakowicz; B. P. Maliwal; H. Cherek; A. Balter, BiochemistryUs, 1983, 22, 1741-1752.

26 L. N. Johnson; D. C. Phillips, Nature, 1965, 206, 761-\&.

2027 T. Imoto; J. A. Rupley; F. Tanaka; L. S. Forster, P Natl Acad Sci USA, 1972, 69, 1151-\&.

28 R. W. Cowgill, Biochimica et Biophysica Acta (BBA) - Protein Structure, 1967, 140, 37-44.

29 A. G. Szabo; D. M. Rayner, J Am Chem Soc, 1980, 102, 554-563.

2530 R. Mcguire; I. Feldman, Biopolymers, 1975, 14, 1095-1102.

31 H. Van Olphen; J. J. Frippiat Data Handbook for Clay Minerals andother Non-Metallic Minerals,; Pergamon Press: London, 1979.

32 M. Kharroubi; S. Balme; F. Henn; J. C. Giuntini; H. Belarbi; A. Haouzi, J Colloid Interf Sci, 2009, 329, 339-345.

3033 R. Guegan, Langmuir, 2010, 26, 19175-19180.

34 R. Guegan, J Colloid Interf Sci, 2011, 358, 485-490.

35 D. V. O'Connor; D. Phillips Time Correlated Single Photon Counting; Academic Press: New-York, 1984.

36 D. W. Marquardt, J Soc Ind Appl Math, 1963, 11, 431-441.

3537 A. Grinvald; I. Z. Steinberg, Analytical Biochemistry, 1974, 59, 583598.

38 J. Durbin; G. S. Watson, Biometrika, 1951, 38, 159-178.

39 J. Durbin; G. S. Watson, Biometrika, 1950, 37, 409-428.

40 J. Durbin; G. S. Watson, Biometrika, 1971, 58, 1-\&.

4041 J. Etheve; P. Dejardin, Langmuir, 2002, 18, 1777-1785.

42 B. Jachimska; A. Kozlowska; A. Pajor-Swierzy, Langmuir, 2012, 28, 11502-11510.

43 A. Violante; A. De Cristofaro; M. A. Rao; L. Gianfreda, Clay Minerals, 1995, 30, 315-336.

${ }_{45} 44$ I. E. Svendsen; L. Lindh; T. Arnebrant, Colloid Surface B, 2006, 53, $157-166$.

45 S. Noinville; M. Revault; H. Quiquampoix; M. H. Baron, J Colloid Interf Sci, 2004, 273, 414-425.

46 N. Helassa; M. Revault; H. Quiquampoix; P. Dejardin; S. Staunton; S.

50 Noinville, J Colloid Interf Sci, 2011, 356, 718-725.

47 L. C. Sang; M. O. Coppens, Phys Chem Chem Phys, 2011, 13, 66896698.

48 T. Zoungrana; W. Norde, Colloid Surface B, 1997, 9, 157-167.

49 C. F. Wertz; M. M. Santore, Langmuir, 2002, 18, 1190-1199.

5550 E. Nishimoto; S. Yamashita; A. G. Szabo; T. Imoto, Biochemistry-Us, 1998, 37, 5599-5607.
51 E. Nishimoto; S. Yamashita; N. Yamasaki; T. Imoto, Biosci Biotech Bioch, 1999, 63, 329-336.

52 L. P. McMahon; H. T. Yu; M. A. Vela; G. A. Morales; L. Shui; F. R. 60 Fronczek; M. L. McLaughlin; M. D. Barkley, J Phys Chem B, 1997, 101, 3269-3280.

53 J. B. A. Ross; H. R. Wyssbrod; R. A. Porter; G. P. Schwartz; C. A. Michaels; W. R. Laws, Biochemistry-Us, 1992, 31, 1585-1594.

54 J. Narayanan; X. Y. Liu, Biophys J, 2003, 84, 523-532.

6555 I. Pastor; M. L. Ferrer; M. P. Lillo; J. Gomez; C. R. Mateo, J Phys Chem B, 2007, 111, 11603-11610.

56 P. Valeur; G. Weber, Photochemistry and Photobiology, 1977, 25, 441-444.

57 X. H. Shen; J. R. Knutson, J Phys Chem B, 2001, 105, 6260-6265.

7058 D. P. Zhong; S. K. Pal; D. Q. Zhang; S. I. Chan; A. H. Zewail, P Natl Acad Sci USA, 2002, 99, 13-18. 